\title{
PERANCANGAN KAMPANYE SOSIAL DAMPAK GAME ONLINE BAGI REMAJA DI KOTA PALEMBANG
}

\author{
Sapar Junoko ${ }^{1)}$, Yosef Yulius ${ }^{2)}$, Didiek Prasetya ${ }^{3)}$ \\ 1) 22) Program Studi Desain Komunikasi Visual, Fakultas Ilmu Pemeritahan dan Budaya Universitas Indo Global \\ Mandiri Jl Jend. Sudirman No. 629 KM. 4 Palembang 30129 \\ Email :safarjuni22@gmail.com ${ }^{1)}$,yosef_dkv@uigm.ac.id ${ }^{2)}{ }^{\text {diart_26@yahoo.com }}{ }^{3)}$
}

\begin{abstract}
ABSTRACK
Technological progress is something that can not be avoided in today's life. One of the results of technological development is the internet, one of its benefits is as a means of entertainment, for example to play online games. Online games themselves are not only played from computer games but can also be played on smartphones, online games are much loved by teenagers because online games themselves are a means of entertainment for them but most teenagers are addicted to playing online games. Online games themselves have positive and negative impacts, but if playing excessive online games can have positive impacts which are definitely addicted to playing continuously. The main study of this research focuses on the identification, analysis and design of Video Motion Graphic works and other supporting media. This design uses premedia media planning methods, playing media and media follow-up. Data collected through, observation, interviews, literature and website. The data is then identified, classified, selected, then analyzed using the $5 \mathrm{~W}+1 \mathrm{H}$ method and interpreted according to the text and context. The design of the social media campaign of the impact of online games for teens in the city of Palembang as a visual communication media which is part of the design discussion. This design aims to encourage adolescents to reduce and reduce the number of addictions due to online games especially teenagers in the city of Palembang in order to be able to balance between playing online games and learning to get achievements in education.
\end{abstract}

Key word: Online Games, Motion Graphic Video, Social Campaign, Internet, Smartphone

\begin{abstract}
ABSTRAK
Kemajuan teknologi adalah sesuatu yang tidak bisa dihindari dalam kehidupan saat ini. Salah satu hasil dari perkembangan teknologi adalah internet, salah satu manfaatnya adalah sebagai sarana hiburan, misalnya untuk bermain game online. Game online sendiri tidak hanya dimainkan dari permainan game komputer saja melainkan juga dapat dimainkan di Smartphone, game online banyak digemari oleh anak remaja dikarenakan game online sendiri merupakan sarana hiburan bagi mereka namun kebanyakan remaja kecanduan bermain game online. Game online sendiri memiliki dampak positif dan negatifnya namun jika bermain game online yang berlebihan dapat menimbulkan dampak positif yang pastinya kecanduan untuk bermain terus menerus. Kajian utama penelitian ini dititikberatkan pada identifikasi, analisa dan perancangan pada karya Video Motion Graphic dan media pendukung lainnya. Perancangan ini menggunakan metode perencanaan media premedia, main media dan follow up media. Data dikumpulkan melalui, observasi, wawancara, literatur dan website. Data tersebut kemudian diidentifikasi, diklasifikasi, diseleksi, selanjutnya dianalisis menggunakan metode $5 W+1 H$ dan diinterpretasikan sesuai teks dan konteksnya. Perancangan media kampanye sosial dampak game online bagi remaja di kota Palembang sebagai media komunikasi visual yang merupakan bagian dalam pembahasan perancangan ini. Perancangan ini bertujuan mengajak remaja untuk mengurangi dan menekan angka kecanduan akibat game online khusunya remaja dikota Palembang agar dapat menyeimbangkan antara bermain game online dan belajar untuk mendapatkan prestasi dibidang pendidikan.
\end{abstract}

Kata kunci: Game Online, Video Motion Graphic, Kampanye Sosial, Internet, Smartphone 


\section{Pendahuluan}

Pada zaman modern sekarang ini, dunia tengah dilanda perkembangan dalam bidang ilmu pengetahuan dan teknologi. Perkembangan ilmu dan teknologi yang semakin pesat ternyata membawa perubahan dalam segala lapisan kehidupan. Kemajuan teknologi adalah sesuatu yang tidak bisa dihindari dalam kehidupan ini, karena kemajuan teknologi akan berjalan setiap tahunnya. Kemajuan teknologi ini menyebabkan perubahan yang begitu besar pada kehidupan manusia dengan segala peradaban dan kebudayaannya, saat ini kemajuan teknologi telah mempengaruhi gaya hidup dan pola pikir masyarakat khususnya di kalangan remaja. Salah satu hasil dari perkembangan teknologi adalah internet. Seiring dengan perkembangan zaman teknologi internet semakin berkembang pesat, salah satu manfaatnya adalah sebagai sarana hiburan, misalnya untuk bermain game. Permainan video game dengan menggunakan jaringan internet tersebut dikenal sebagai game online. Game online sendiri sekarang sangat mudah diakses baik itu melalui Smartphone ataupun bisa juga dari komputer.

Mengutip sumber data dari website Kementerian Komunikasi dan Informatika Republik Indonesia (KOMINFO) Jumlah pengguna internet tahun 2017 telah mencapai 143,26 juta jiwa atau setara dengan 54,68 persen dari total jumlah penduduk Indonesia. Jumlah tersebut menunjukan kenaikan sebesar 10,56 juta jiwa dari hasil survei pada tahun 2016.

Sedangkan di Kota Palembang sendiri Mengutip sumber data dari Asosiasi Penyelenggara Jasa Internet Indonesia (APJII) jumlah pengguna internet tahun 2018 di kota Palembang berjumlah 64,4\% di dominasi untuk bermain game online. Untuk pengguna internet berdasarkan jenis kelamin, terdiri dari perempuan sebanyak 48,57 persen, dan lelaki sebanyak 51,43 persen, kemudian untuk berdasarkan usia, angka terbesar ditunjukan oleh masyarakat berumur 19 - 34, yakni sebesar 49,52 persen.

Game online tidak hanya dimainkan dari permainan game komputer saja melainkan juga dengan berbagai macam jenis game handheld. Semuanya berawal dari permainan Playstation 2, PSP, Nitendo DS dan Xbox. Tadinya game yang di tawarkan dari playstation 2 dan Xbox yang bisa di hubungkan ke internet hanya beberapa saja. Namun di tahun 2008 dipastikan, hampir semua game didalam Playstation 3, PSVita, Xbox one dan Komputer bisa dimainkan secara online. Selain itu perusahaan hand phone ditahun 2009 hingga sekarang sudah mulai memproduksi perangkat-perangkat hand phone yang lebih canggih lagi, diantaranya yang paling terkenal perangkat lunaknya pada masa kini adalah sistem Android, dan Ios.
Kehadiran video game di tengah-tengah laju teknologi sendiri telah membawa pengaruh besar terhadap perkembangan pribadi dan adaptasi remaja, bahkan tidak sedikit remaja yang berubah menjadi pecandu game sehingga lupa pada jati diri mereka yang sesungguhnya. Waktu yang semestinya dipergunakan untuk bermain dengan teman sebaya atau belajar, telah disita demi bisa duduk berlamalama untuk bermain game. Fenomena maraknya game online juga bisa dilihat dengan banyaknya penyedia jasa kuota internet yang murah mulai dari harga mulai Rp.8.000 sudah bisa mendapatkan kuota internet dan dapat menikmati game online yang ingin dimainkan.

Dalam perancangan ini penulis akan membahas kampanye sosial dampak bermain game online bagi remaja di Kota Palembang, pembahasan ini muncul dari banyaknya kasus kecanduan game online di negara-negara seperti Taiwan, dan Jepang hingga menimbulkan kematian saat bermain game online, di indonesia sendiri kasus kecanduan game online mengakibatkan remaja mengalami gangguan mental akibat terlalu banyak interaksi dengan dunia virtual. Dengan adanya kampanye ini diharapkan mampu menyadarkan, mengurangi, dan menekan remaja untuk tidak bermain game online yang berlebihan, sampai mengakibatkan kematian supaya tidak terjadi di Indonesia khususnya kota Palembang.

Berlandaskan dari faktor tersebut Penulis berinisiatif untuk merancang suatu media kampanye yang edukatif serta mampu memberi pengetahuan baru kepada remaja tentang dampak bermain game online. Dampak bermain game online sendiri dapat mengakibatkan dampak di aspek kesehatan jika dilakukan berlebihan dapat mengakibatkan kematian. Peranan cabang keilmuan desain komunikasi visual pada media-media promosi kesehatan sangat penting, dengan ilmu desain komunikasi visual, media-media promosi kesehatan akan terpublikasi secara lebih komunikatif, aplikatif dan tepat sasaran (Yulius, Y : 2016).

Kampanye sosial yang berjudul Perancangan Kampanye Sosial Dampak Game Online Bagi Remaja Di Kota Palembang diharapkan mendapatkan ilmu pengetahuan bagi masyarakat di Kota Palembang khusunya bagi remaja. Media utama kampanye ini adalah video motion Graphic dengan media pendukung berupa, poster, flyer, Xbanner, kotak pensil, pouch handphone, dan $T$ Shirt, target sasaran pada kampanye tersebut yaitu kalangan remaja di Kota Palembang.

Adapun analisa data $5 \mathrm{~W}+1 \mathrm{H}$ yang telah Penulis lakukan mengenai Perancangan Kampanye Sosial Dampak Game Online Bagi Remaja Di Kota Palembang, yaitu: 


\section{1). What To Say}

Bermain game online yang berlebihan akan berdampak buruk, banyak remaja yang gemar bermain game mengalami penurunan prestasi, mengalami masalah dengan kepribadiannya, menderita penyakit, melakukan tindak kriminal dan bahkan menyebabkan kematian. Bagi kebanyakan remaja, game merupakan bagian tak terpisahkan dari keseharian mereka, sedangkan sebagian orang tua menuding game sebagai penyebab nilai anak turun, anak tak mampu bersosialisasi, dan tindakan kekerasan yang dilakukan remaja.

2). Why To Say

Pembahasan ini muncul dari banyaknya kasus kecanduan game online di negara-negara seperti Taiwan, dan Jepang hingga menimbulkan kematian saat bermain game online, di indonesia sendiri kasus kecanduan game online mengakibatkan remaja mengalami gangguan mental akibat terlalu banyak interaksi dengan dunia virtual. Dengan adanya kampanye ini diharapkan mampu menyadarkan, mengurangi, dan menekan remaja untuk tidak bermain game online yang berlebihan sampai mengakibatkan kematian tidak terjadi di Indonesia khususnya kota Palembang.

3). Who To Say

Perancangan kampanye sosial dampak game online bagi remaja di kota Palembang ini memiliki target audience yang telah ditentukan meliputi remaja sampai dewasa serta masyarakat umum di Palembang yang dibagi menjadi beberapa bagian. Yaitu :

\section{Geografis}

Primer : Palembang

Sekunder : Sumatera Selatan

\section{Demografis}

a. Gender

Primer : Laki-laki

Sekunder : Perempuan

b. Usia

Primer : :12-21 Tahun

Sekunder : 21-35 tahun

\section{c. Pendidikan}

Primer : SD, SMP, SMA Dan Mahasiswa

Sekunder : Masyarakat Umum

\section{d. Strata}

Primer : Masyarakat Menengah Kebawah

Sekunder : Masyarakat Menengah Keatas

\section{Psikologis}
a. Emosional
b. Praktis

c. Komunikatif di dunia maya

d. Kesepian

e. Mudah

f. Punya dunia sendiri

\section{Behavioristik}
a. Pemarah
b. Butuh liburan
c. Suka tantangan baru
d. Kurang bersosialisasi di dunia nyata

\section{4). When To Say}

Mengenai pertanyaan kapan kampanye ini harus dilakukan, bahkan sebelum rancangan ini disampaikan kepada target sasaran, kampanye dampak bermain game online yang berlebihan haruslah selalu dilakukan. Mengingat banyak remaja yang kecanduan game online sehingga mereka lupa waktu dan sampai mengakibatkan sejumlah masalah kesehatan bahkan kematian.

5). Where To Say

Kampanye ini akan dikampanyekan dan disebarkan di sekolah-sekolah baik itu SD, SMP, SMA dan Universitas-universitas yang ada di kota Palembang. Selain itu perlu memanfaatkan media elektronik, cetak dan media online, sehingga pesan dari kampanye ini sampai ke target sasaran.

6). How To Say

1. Pre Media : Poster, flyer, Maskot, dan Logo

2. Main Media : Video Motion Graphic

3. Follow Up Media : Kotak Pensil, Pouch Handphone, Pena, Notes, Selempang, T-Shirt, $X$-Banner.

Perancangan ini dibuat melalui beberapa langkah pendekatan serta alur kegiatan yang bisa menyadarkan motivasi target sasaran untuk mengurangi kecanduan bermain game online yang berlebihan. Dengan menarik perhatian masyarakat melalui media Visual sangatlah tepat untuk tahun milenial saat ini dan dengan melalukan promosi rutin ke sekolah-sekolah dan universitas yang ada di kota Palembang sehingga kampanye ini memiliki manfaat yang berguna bagi masyrakat khususnya anak remaja yang ada di kota Palembang. Dengan melakukan dan membuat media yang tepat sasaran, nantinya kampanye ini tidak hanya rutin dilakukan di sekolah dan universitas saja tetapi akan di kampanyekan di tempat-tempat umum yang sering di kunjungi oleh anak kalangan remaja agar dapat mudah di pahami oleh remaja itu sendiri. 


\section{Pembahasan}

Game Online adalah media elektronik yang menyuguhkan berupa tampilan gerak, warna, suara yang memiliki aturan main dan terdapat tingkatan tertentu, yang bersifat menghibur dan bersifat adiktif. Secara operasional game online adalah sebuah permainan yang memiliki konsep permainan yang menarik, memiliki teknologi grafis dan memiliki efek-efek yang luar biasa. Game Online berasal dari kata game dan online. Game adalah dasar permainan dan Online adalah langsung dengan bantuan jaringan internet. Para pemain game online hanya membutuhkan biaya sekiranya Rp.2.000 perjam-nya atau Rp.5.000 perdua jam nya, jika memainkan game online di warung internet atau game center.

Sedangkan bagi para pengguna Smartphone hanya membutuhkan biaya paket data saja, dengan harga paket berkisar Rp.20.000 atau Rp.35.000 saja perbulannya. Kita sudah dapat menikmati fasilitas game online di Smartphone yang ada. Harga-harga yang terbilang cukup murah dengan dampak dan efek yang cukup mengkhawatirkan. Mengutip sumber data dari survei Asosiasi Penyelenggara Jasa Internet Indonesia (APJII) pada tahun 2017 jumlah kepemilikan perangkat untuk komputer atau laptop berjumlah $25,72 \%$ sedangkan kepemilikan smartphone atau tablet berjumlah 50,08\%. Dari hasil survei yang dilakukan APJII Jumlah kepemilikan perangkat Smartphone dan tablet lebih banyak dari kepemilikan Komputer dan Laptop dikarenakan penggunaan Smartphone dan Tablet sangatlah mudah dan simple bisa dipakai dimana saja. Hal ini tidak lepas dari perkembangan teknologi yang ada sekarang, Saat ini Smartphone memiliki dua perangkat lunak yaitu menggunakan perangkat lunak sistem Android, dan Ios. Android dan Ios ini merupakan sistem perangkat lunak pada sebuah Smartphone yang dimana perangkat lunak tersebut berguna untuk memudahkan pengguna untuk memakai Smartphone. Selain untuk memudahkan ternyata perangkat lunak android dan Ios ini juga mendukung sistem game didalam aplikasi Smartphone pada saat ini.

Mengutip sumber data dari website Kementerian Komunikasi dan Informatika Republik Indonesia (KOMINFO) Jumlah pengguna internet tahun 2017, telah mencapai 143,26 juta jiwa atau setara dengan 54,68 persen dari total jumlah penduduk Indonesia. Jumlah tersebut menunjukan kenaikan sebesar 10,56 juta jiwa dari hasil survei pada tahun 2016. Sedangkan di Kota Palembang sendiri Mengutip sumber data dari Asosiasi Penyelenggara Jasa Internet Indonesia (APJII) jumlah pengguna internet tahun 2018 di kota Palembang berjumlah 64,4\% di dominasi untuk bermain game online. Dari data yang didapat laki-laki mendominasi penggunaan internet di Indonesia pada tahun 2019, kemudian dari aspek usia, usia yang banyak menggunakan internet mulai dari usia 15-19 tahun. 
Dari data yang didapat laki-laki mendominasi penggunaan internet di Indonesia pada tahun 2019, kemudian dari aspek usia, usia yang banyak menggunakan internet mulai dari usia 15-19 tahun. Dapat dilihat bahwa remaja adalah pengguna internet terbesar di indonesia dengan berbagai aktifitas mulai dari browsing internet, menonton video, mengunduh software, sosial media, hingga bermain game online.

( https://kominfo.go.id Di akses 13 Maret 2019 )

\section{A. Konsep Media}

Perancangan Kampanye sosial dampak game online bagi remaja di kota Palembang memiliki beberapa tahapan media yang akan digunakan pada perancangan. Gaya tampilan desain yang akan dipakai adalah menggunakan jenis gaya desain pixel art, pixel art adalah salah satu computer artwork tertua yang kini mengalami masa kebangkitannya kembali, pertama kali muncul sebagai grafis di dalam permainan video game namun kemudian terus berkembang menjadi sebuah disiplin dan metode yang terpopuler untuk menciptakan artwork bergaya retro. Menurut Widya Widjaja (2016) Pixel art sendiri adalah jenis tampilan game pertama kali, dengan dipilihnya gaya tampilan desain ini diharapkan bisa membawa suasana seperti zaman dahulu dimana game belum ada dampak yang sangat buruk bagi yang memainkannya.

Strategi media adalah langkah yang dilakukan untuk mencapai tujuan menyampaikan informasi atau pesan kepada masyarakat. Strategi media yang ditetapkan meliputi segmentasi media, panduan media, program media, dan biaya media. Pada perancangan kampanye ini menargetkan sasaran kepada remaja kota Palembang sebagai target primer dan remaja Sumatera Selatan sebagai target sekunder. Mengenai hal ini, strategi media yang digunakan merupakan media-media yang sangat dekat dengan masyarakat, namun dengan konsep perancangan yang komunikatif dan persuasif sehingga dapat dimengerti. Adapun media yang digunakan menggunakan ilustrasi yang terkesan sederhana, namun memiliki makna dalam penyampaian pesan.

Penulis menggunakan media menjadi pre media, main media dan follow up media sebagai perencanaan media. Baik itu pre media, main media ataupun follow up media ketiga nya terbagi menjadi kategori media cetak dan media elektronik. Media cetak merupakan media statis dan mengutamakan pesan-pesan visual yang dihasilkan dari proses pencetakan, sedangkan pada media elektronik merupakan media yang memiliki proses kerja dan tata cara pengkomunikasian berdasarkan pada prinsip elektronik. 
Pada gagasan kreatif ini, penulis mengambil tema “MVP (Most Valuable Player". Gagasan ini diambil dari istilah didalam game, istilah $M V P$ adalah sebuah sebutan kehormatan yang biasanya ditujukan kepada pemain berpenampilan terbaik dalam sebuah permainan game atau bisa juga disebut pemain yang prestasinya yang menonjol daripada pemain lain. Ada makna yang penulis dapat dari tema $M V P$ ini, diharapkan dengan tema ini dapat menyampaikan pesan yang dimaksud, maksud dari pesan yang penulis pilih ini adalah dapat diartikan bahwa MVP adalah sebuah predikat untuk pemain game yang hebat, maka dari itu dengan mengangkat tema ini diharapkan remaja sebagai target utama dalam perancangan kampanye ini nantinya tidak hanya mengejar kehebatan di dalam game saja untuk mendapatkan predikat MVP, tetapi juga mengejar kehebatan untuk mendapatkan predikat MVP di dunia nyata.

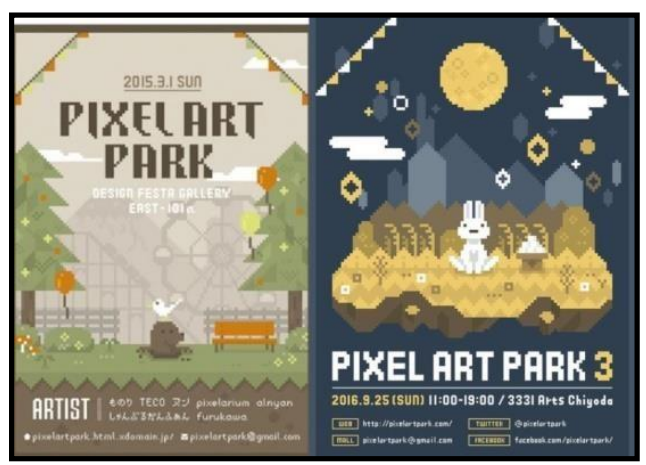

Gambar 1. Poster Pixel Art

Sumber: Z Naddaf,

https://id.pinterest.com

Foto:13 Maret 2019

Pada gaya tampilan desain yang akan dirancang dalam perancangan kampanye sosial dampak game online bagi remaja di kota Palembang ini penulis memilih tampilan desain Pixel art. Pixel art adalah salah satu computer artwork tertua yang kini mengalami masa kebangkitannya kembali, pertama kali muncul sebagai grafis di dalam permainan video game namun kemudian terus berkembang menjadi sebuah disiplin dan metode yang terpopuler untuk menciptakan artwork bergaya retro. Pixel art sendiri adalah jenis tampilan game pertama kali, dengan dipilihnya gaya tampilan desain ini diharapkan bisa membawa suasana seperti zaman dahulu dimana game belum ada dampak yang sangat buruk bagi yang memainkannya.

Pixel art adalah seni digital yang digunakan ketika game komputer berbasis $2 \mathrm{~d}$ pertama kali muncul. Pixel art semakin jarang digunakan ketika teknologi visualisasi $3 \mathrm{~d}$ muncul. Sekarang, dengan adanya game mobile dan gadget-gadget atau handheld game terbaru seperti Gameboy Advance dan Nintendo DS, pixel art digunakan kembali.

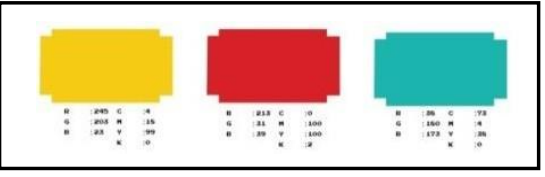

Gambar 2. Warna-warna yang dipakai Sumber: Sapar Junoko

Foto : 10 November 2019

Pada bagian warna perancang mengambil tone dengan warna utama dan warna pendukung yang sesuai dengan karakteristik anak remaja. Pada perancangan ini, perancang mengambil warna utama warna orange dan kuning untuk warna pendukung.

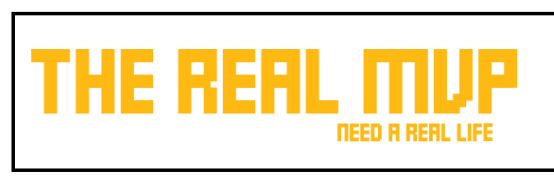

Gambar 3. Typografi FFF Forward Sumber: www.dafont.com

Typografi dan tampilan typeface dalam perancangan ini nantinya akan menyesuaikan dengan konsep yang telah penulis pilih. Jenis yang digunakan dalam font ini adalah jenis pixel art. Pixel art adalah typografi yang dikenal dengan nama Screen Font, jenis font ini dibuat dengan tujuan mengisi tampilan layar kompuer. Font pixel art terlihat tajam karena strukturnya berdasarkan pada bentuk kotak, kemudian jenis font pixel art populer karena kejelasannya walaupun dalam ukuran kecil. Di samping itu, font Pixel biasanya ditampilkan dalam warna-warna kontras seperti hitam dan putih, bukan abu-abu.

\section{B. Final Desain}

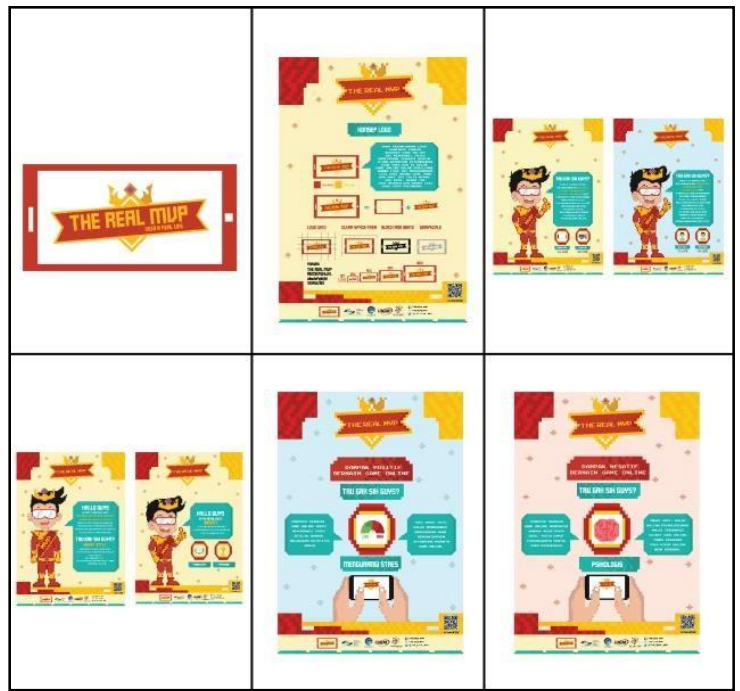

Gambar 4. Final Desain Logo, Konsep Logo, Flyer, Dan Poster

Dibuat Oleh: Sapar Junoko 
Final desain logo, konsep logo, flyer, dan poster memiliki gaya tampilan desain pixel art, desain logo sendiri memiliki konsep mengambil sebuah objek smartphone dengan menggunakan logotype bertuliskan "The Real MVP" dengan ciri khas warna merah dan kuning emas, kemudian di dalam konsep logo ada panduan yang benar dalam penggunaan logo dikampanye ini guna agar logo ini dapat digunakan dengan baik, kemudian di dalam flyer terdapat informasi mengenai data-data pengguna internet di indonesia dan kota palembang dengan ukuran kertas A5. Kemudian yang terakhir di dalam poster terdapat dua bagian yaitu poster utama dan poster dampak negatif dan positif, isi poster utama merupakan sebuah ajakan untuk menerapkan permainan game online di kehidupan nyata sedangkan poster dampak negatif dan positif merupakan poster yang mempunyai isi sebuah informasi tentang apa saja dampak negatif dan dampak positif dari bermain game online.

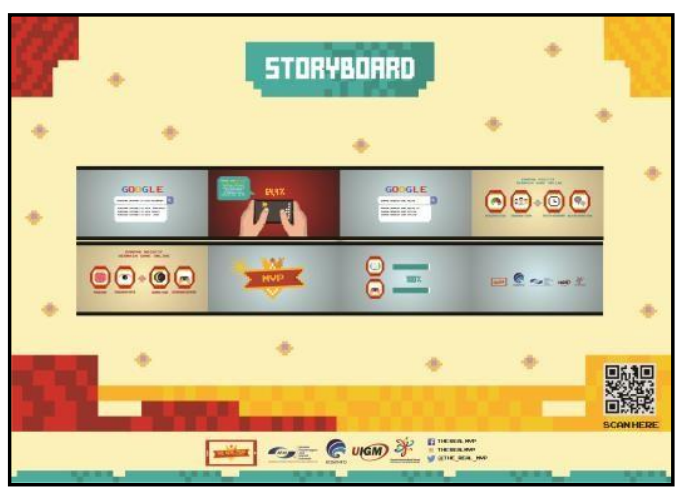

\section{Gambar 5. Final Desain Main \\ Media Video Motion Graphic \\ (Storyboard)}

Dibuat Oleh: Sapar Junoko

Main media yang dipilih dalam perancangan ini adalah sebuah video motion graphic yang memiliki durasi 2 menit 03 detik pesan yang ada di dalam video ini merupakan sebuah ajakan dan sebuah informasi mengenai dampak bermain game online. Video ini memiliki resolusi 1920x1080 pixel target penggunaan media video ini adalah youtube, sosial media, TVC, dan videotron. Main media yang dipilih untuk menyesuaikan target kampanye ini yaitu remaja, dimana di zaman millenial ini video dapat di akses dimana saja dan siapa saja oleh karna itu video dipilih menjadi main media di dalam kampanye dampak game online ini. Video ini di buat animasinya menggunakan aplikasi After Effect dan Premiere, untuk membuat desain nya di aplikasi Illustrator setelah desain selesai barulah objek-objek tersebut di bikin animasinya di kedua aplikasi tersebut After Effect dan Premiere

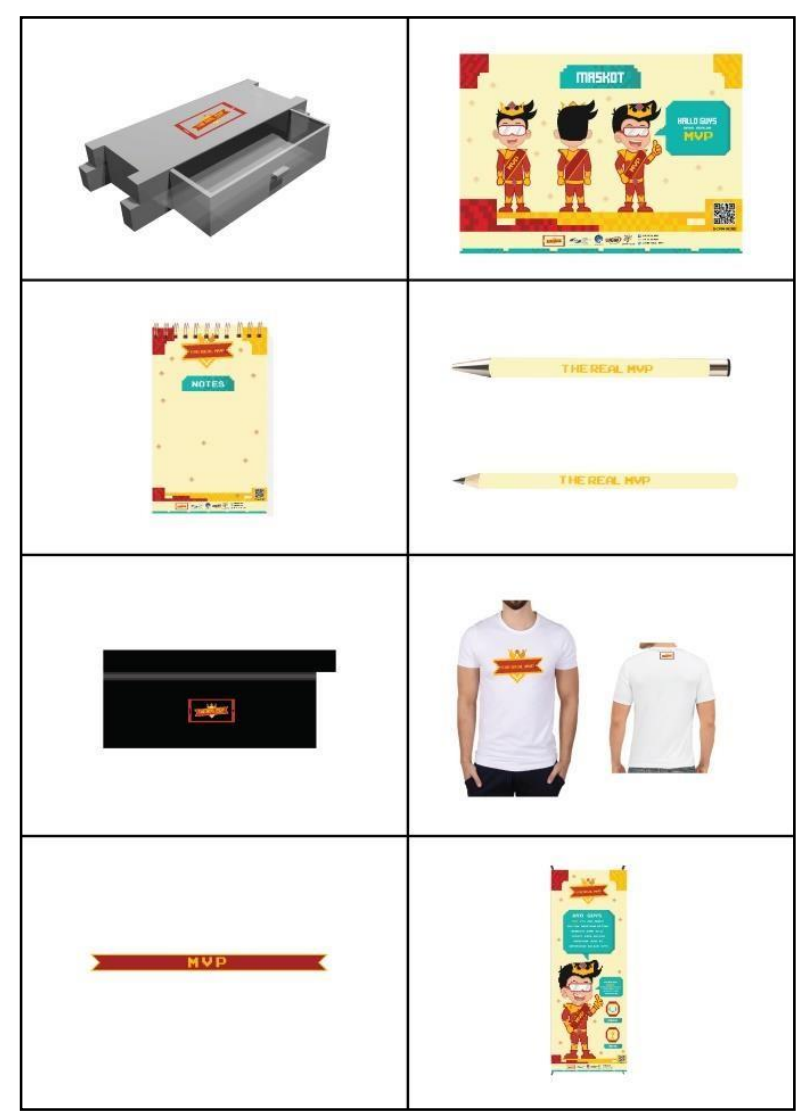

Gambar 6. Final Desain Follow Up Media

Dibuat Oleh: Sapar Junoko

Final desain follow up media ini meliputi kotak pensil, maskot, buku notes, pena, pensil, pouch handphone, $\mathrm{t}$-shirt, selempang, dan $\mathrm{x}$-banner. Semua media ini akan menjadi penunjang untuk menginformasikan kampanye ini kepada target audience yaitu remaja yang ada di kota Palembang, seperti media kotak pensil,t-shirt, pouch hp,pena dan pensil akan menjadi merchandise yang nantinya akan ada sebuah desain yang berupa pesan ajakan dan menyadarkan di setiap medianya dan semua media ini akan di bagikan disetiap event pameran yang di laksanakan. Target utama kampanye ini akan diadakan di sekola dan universitas yang ada di kota Palembang serta tempat-tempat umum yang sering di kunjungi oleh anak kalangan remaja yang ada di kota Palembang sehingga kampanye ini agar tepat sasaran. Dibuatnya follow up media ini menjadi sebuah penunjang dalam kampanye ini tidak hanya pre media dan main media saja yang penting tetapi media pendukung ini sangat berperan penting juga dalam kampanye ini agar berhasil menyampaikan apa maksud dari kampanye ini. 


\section{Pameran Karya}

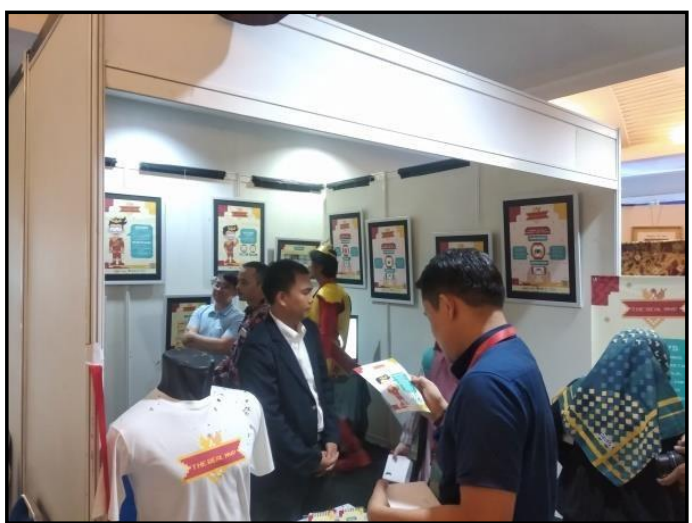

Gambar 17. Pameran Tugas Akhir Dibuat Oleh: Sapar Junoko

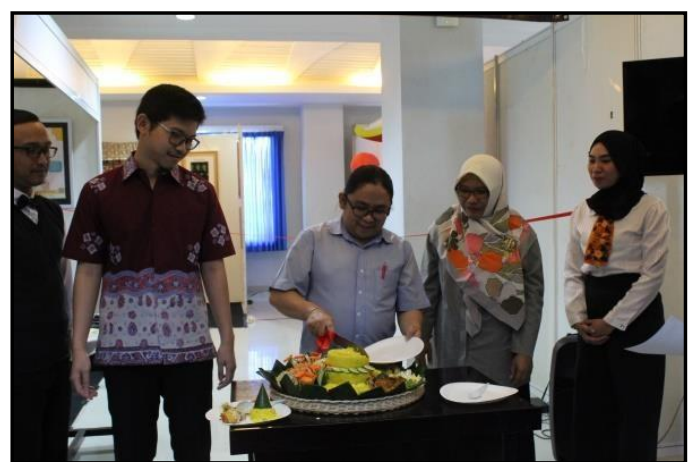

Gambar 18. Pameran Tugas Akhir Dibuat Oleh: Sapar Junoko

\section{Kesimpulan}

Perancangan Tugas Akhir ini merupakan suatu karya visual yang digunakan untuk mengkomunikasikan dam mengajak masyarakat kearah hidup yang lebih baik. Dalam hal ini perancangan kampanye sosial dampak game online bagi remaja kota Palembang adalah salah satu bentuk ajakan dalam penerapan mengurangi kecanduan game online. Dengan perancangan kampanye ini, para target sasaran khususnya remaja di kota Palembang dapat tertarik dan menerapkannya dalam kehidupan sehari-hari. Melalui perancangan ini penulis belajar bahwa dalam membuat suatu perancangan diperlukan banyak hal mendasar seperti pengumpulan data yang kongkrit, pemahaman bagaimana membentuk visual objek-objek yang diilustrasikan kedalam bentuk ilustrasi digital sehingga dapat merepresentasikan maksud dari objek yang asli, kemudian bagaimana membuat konsep yang sesuai dengan kampanye akan dilakukan.
Melalui peracangan ini pula penulis semakin menyadari bahwa ruang lingkup Desain Komunikasi Visual dapat begitu luas dan mencangkup berbagai aspek dalam kehidupan manusia. Melalui perancangan kampanye menggunakan media yang inovatif dan menarik dapat meningkatkan minat masyarakat khususnya para remaja dalam penerapan sebuah kampanye. Dengan pemilihan media-media utama dan pendukung yang sesuai dan melalui proses observasi serta studi bentuk dan metode pengumpulan data lain sebagainya dalam. Perancangan kampanye sosial dampak game online bagi remaja kota Palembang sehingga perancangan ini dapat sesuai dengan apa yang ingin penulis sampaikan.

\section{Daftar Pustaka}

Sunmaryati, Reni, Resiani. (2017). Transformasi Perkembangan game dari masa ke masa, Jurnal Sejarah Game. Vol. 1 No.2:18-20.

Masya Hardiyansyah. (2016). Faktor- faktor yang mempengaruhi perilaku gangguan kecanduan game online. Jurnal Perilaku kecanduan game online. Vol. 1 No.2:157-158.

Widjaja, Widya. (2016). Perkembangan game dari masa ke masa, Jurnal Perkembangan video game. Vol. 2 No.3:25-29.

https://kominfo.go.id/content/detail/12640/tentangjumlah-pengguna-internet- 2017. Diakses pada 13 Maret 2019.

https://web.kominfo.go.id/sites/default/files/201 70210-Indikator-TIK-2016-BalitbangSDMKominfo.pdf. Diakses pada 13 Maret 2019.

Yulius, Y. 2016. Peranan Desain Komunikasi Visual Sebagai Pendukung Media Promosi Kesehatan.Jurnal, Desain Dan Budaya, 1(2.) https://Pinterest.com. Diakses pada 13 Oktober 2019. 